\title{
Evaluación de la actividad inmunogénica de una vacuna para profilaxis de la anaplasmosis bovina
}

\author{
Lozina, L.'; Torioni, E.S. ${ }^{2}$; Barbieri, F.'; Del Río, F. ; Ríos, E.E. ${ }^{1}$ \\ ${ }^{1}$ Dpto. Clínicas, Fac. Cs. Vet., Univ. Nac. Nordeste (UNNE), Cabral 2139, Corrientes 3400, Argentina. \\ ${ }^{2}$ Instit. Nac. Tecnol. Agropec. (INTA), Rafaela, Santa Fe, Argentina. \\ E-mail:1lozina@vet.unne.edu.ar
}

\begin{abstract}
Resumen
Lozina, L.; Torioni, E.S.; Barbieri, F.; Del Río, F.; Ríos, E.E.: Evaluación de la actividad inmunogénica de una vacuna para profilaxis de la anaplasmosis bovina. Rev. Vet. 30: 1, 3-6, 2019. El objetivo de este trabajo fue formular una vacuna criopreservada para la prevención de la anaplasmosis y evaluar su actividad inmunogénica. Se utilizó una vacuna monovalente de 2,5 $\times 10^{7}$ eritrocitos bovinos infectados con Anaplasma centrale, criopreservada en glicerol en dosis de 0,5 ml. Para ello se seleccionaron 20 terneros entre 4-10 meses de edad, libres de anaplasmosis, de un establecimiento ubicado en la Provincia de Corrientes, Argentina. El lote fue dividido en dos grupos iguales, uno recibió la vacuna criopreservada y el otro se utilizó como grupo control sin vacunación. Se tomaron muestras de suero a los 0,30 y 60 días post-vacunación (dpv) y se evaluó la inmunidad inducida por la vacuna mediante ensayo por inmunoabsorción ligado a enzimas (ELISA) en suero. A los 15-30-45 y $60 \mathrm{dpv}$ se analizaron muestras de sangre de 3 terneros de cada grupo para la identificación y diferenciación de Anaplasma sp mediante reacción en cadena de la polimerasa (PCR). ELISA resultó negativa para los 20 terneros analizados en el día de la vacunación; a los $30 \mathrm{dpv}$ dos terneros del grupo vacunado resultaron positivos mientras que los terneros del grupo control fueron negativos. A los $60 \mathrm{dpv}$ el $80 \%$ de los terneros del grupo vacunado fue positivo al ELISA y dos animales del grupo control resultaron sospechosos. La PCR reveló la presencia de A. centrale a los $60 \mathrm{dpv}$ no solo en los tres terneros del grupo vacunado sino también en los tres del grupo control, hecho que podría atribuirse a la transmisión horizontal por iatrogenia $\mathrm{o}$ a través de vectores. A. marginale no fue identificado. La falta de detección de anticuerpos específicos a los $60 \mathrm{dpv}$ en dos terneros vacunados, no analizados por PCR, podría responder a un período de incubación más prolongado, y hubiera requerido un control posterior. Se concluye que la vacuna monovalente de $A$. centrale criopreservada confirió una inmunidad adecuada para la profilaxis de la anaplasmosis en terneros, resultando una alternativa válida para establecimientos de zonas libres de garrapatas. Se confirmó la ausencia de $A$. marginale en el rodeo analizado y la transmisión horizontal de la cepa vacunal.
\end{abstract}

Palabras clave: bovino, anaplasmosis, inmunoprofilaxis, controles ELISA y PCR.

\begin{abstract}
Lozina, L.; Torioni, E.S.; Barbieri, F.; Del Río, F.; Ríos, E.E.: Evaluation of the immunogenic activity of a vaccine for the prophylaxis of bovine anaplasmosis. Rev. Vet. 30: 1, 3-6, 2019. The aims of this work were to formulate a cryopreserved vaccine for the prevention of anaplasmosis and to evaluate its immunogenic activity. A monovalent vaccine of $2.5 \times 10^{7}$ bovine erythrocytes infected with Anaplasma centrale in a dose of $0.5 \mathrm{ml}$, cryopreserved in glicerol, was used. Twenty calves were selected, ranging from 4 to 10 months-old, free of anaplasmosis, from an establishment located in the Province of Corrientes, Argentina. The batch was divided into two groups, one received the cryopreserved vaccine and the other was not vaccinated (control group). Serum samples were taken at 0,30 and 60 days after vaccination (dav), and immunity induced by the vaccine was evaluated by ELISA (enzyme-linked immuno sorbent assay). At 15-30-45 and 60 dav, blood samples were analyzed from 3 calves of each group for the identification and differentiation of Anaplasma sp by polymerase chain reaction (PCR). ELISA was negative for the 20 calves analyzed on the day of vaccination; at 30 dav two calves of the vaccinated group were positive while the calves of the control group were negative. At 60 dav, $80 \%$ of the calves in the vaccinated group were positive to ELISA and two animals in the control group were suspect. PCR revealed the presence of $A$. centrale
\end{abstract}


at 60 dav, not only in the three calves of the vaccinated group but also in three animals of the control group. The latter could be attributed to horizontal transmission by iatrogenesis or through vectors. A. marginale was not identified. The lack of detection of specific antibodies at 60 dav in two vaccinated calves, not analyzed by PCR, could correspond to a longer incubation period, and later controls should have been performed. It is concluded that the cryopreserved monovalent vaccine of $A$. centrale confers an adequate immunity for the prophylaxis of anaplasmosis in calves, thus being a valid alternative for those establishments of tick-free zones. Absence of $A$. marginale as well as horizontal transmission of the vaccine strain were confirmed.

Key words: bovine, anaplasmosis, immunoprophylaxis, ELISA and PCR controls.

\section{INTRODUCCIÓN}

La anaplasmosis bovina es una enfermedad infecciosa, aguda o crónica, caracterizada por presentar anemia, ictericia e hipertermia, entre otros síntomas. El agente causante es la rickettsia Anaplasma marginale, que invade los glóbulos rojos produciendo su destrucción. Es transmitida por diferentes mecanismos, entre otros por infección intrauterina, por picadura de insectos hematófagos, o iatrogénicamente (castración, descorne o utilización de instrumental contaminado) ${ }^{7}$.

Los métodos actuales de control de la enfermedad involucran, en primer lugar, al tratamiento farmacológico de los animales afectados, mediante oxitetraciclina o imidocarb. Luego de controlar la erradicación de los vectores, como prevención se recomienda la vacunación con cepas de Anaplasma centrale, práctica que garantiza un estado de fuerte protección inmunológica ${ }^{9}$.

El método inmunoprofiláctico constituye una herramienta importante utilizada en nuestro país, de comprobada eficacia para controlar el impacto de anaplasmosis y babesiosis en los sistemas de producción ganadera. Consiste en aplicar un inmunógeno a base de agentes parásitos atenuados de Babesia bigemina, $\mathrm{Ba}$ besia bovis y Anaplasma centrale, desarrollado por el Instituto Nacional de Tecnología Agropecuaria (INTA). Existen disponibles dos presentaciones de esta vacuna, una fresca (con duración de 7 días) y otra criopreservada con una viabilidad de 2 años desde la fecha de elaboración.

En áreas libres de la garrapata Rhipicephalus (Boophilus) microplus, la babesiosis no representa un problema, al contrario de lo que sucede con la anaplasmosis, requiriendo la utilización de la vacuna ultracongelada conteniendo solo $A$. centrale $^{8,10}$.

Por lo expuesto, en el presente trabajo se formuló una vacuna criopreservada para la prevención de la anaplasmosis, evaluándose su actividad inmunogénica.

\section{MATERIAL Y MÉTODOS}

Vacuna monovalente. La composición cuali-cuantitativa de cada dosis de $0,5 \mathrm{ml}$ fue de $2,5 \times 10^{7}$ eritrocitos infectados con $A$. centrale M1, 125 UI de penicilina $\mathrm{G}$ sódica, $125 \mu \mathrm{g}$ de sulfato de estreptomicina y $0,5 \mathrm{ml}$ de solución salina balanceada con glicerol 1,5 M. Esta presentación se formuló a través de la suspensión de eritrocitos con la adición de glicerol como criopreservador. Esta mezcla se envasó en pajuelas y se expuso a una fase de vapor de nitrógeno líquido, congelando a una tasa de $20^{\circ} \mathrm{C}$ por minuto en una unidad de congelación programable. Cuando la temperatura llegó a $-196^{\circ} \mathrm{C}$ las pajuelas se trasladaron rápidamente a un termo de nitrógeno líquido.

Animales. Se seleccionaron veinte bovinos, hembras, mestizos de Hereford, entre cuatro y seis meses de edad. El lote se dividió aleatoriamente en dos grupos de diez animales cada uno. El primer grupo fue inoculado con la vacuna y el segundo grupo ofició como testigo. Los animales fueron adecuadamente identificados con caravanas (Tabla 1), tras lo cual se procedió a la inoculación de la vacuna monovalente conservada en termos de nitrógeno líquido a $-196^{\circ} \mathrm{C}$. Posteriormente, se envió el lote completo (inoculados y controles) a un corral con comedero de autoconsumo. El ensayo experimental se llevó a cabo en un campo de la Provincia de Corrientes, a $37 \mathrm{~km}$ de Sauce, localidad ubicada por debajo del paralelo $30^{\circ} \mathrm{S}$.

Determinación de la actividad inmunogénica e identificación de Anaplasma sp. Se obtuvieron muestras de suero de todos los animales incluidos en la experiencia en los 0, 30 y 60 días post-vacunación. La presencia de anticuerpos contra la proteína mayor de superficie de Anaplasma sp (MSP-5) se determinó mediante ensayo por inmunoabsorción ligado a enzimas (ELISA competitivo). Asimismo, a los días 15, 30, 45 y 60 se tomaron muestras de sangre con anticoagulante de seis animales, tres de cada grupo, para la identificación y diferenciación de Anaplasma sp mediante reacción en cadena de la polimerasa (PCR anidada). Estos ensayos se realizaron en el Servicio de Diagnóstico Animal de la Estación Experimental INTA (Rafaela, Santa Fe, Argentina), siguiendo el procedimiento descrito por especialistas en el tema ${ }^{12}$.

Evaluación clínica. Durante todo el ensayo, principalmente a partir de los 30 días (período de patencia de Anaplasma sp), se observó el estado general de los 
animales y los posibles efectos adversos en respuesta a la inmunización.

\section{RESULTADOS Y DISCUSIÓN}

Los resultados arrojados por el ensayo ELISA se midieron en porcentaje de positividad respecto de un suero de referencia positivo. El punto de corte fue de $28 \%$. Se tomaron como sospechosos a los valores cercanos al $28 \%$, entre 25 y $40 \%$. El 100\% de los animales muestreados al día 0 resultaron negativos.

El análisis serológico obtenido a los 30 días reveló que el $20 \%$ de los animales inoculados resultaron positivos y el $100 \%$ de los pertenecientes al grupo control fueron negativos.

Transcurridos 60 días, se pudo determinar que el $80 \%$ de los animales vacunados obtuvieron títulos de anticuerpos contra Anaplasma sp y 2 animales resultaron sospechosos en el grupo control, como indica la Tabla 1.

Los resultados obtenidos a partir de la PCR de los días 15, 30, 45 y 60 se muestran en la Tabla 2. Mediante la PCR se pudo confirmar que los animales que resultaron positivos en los ensayos de ELISA, fueron a consecuencia de la respuesta de la cepa vacunal en el sistema inmunológico de los animales.

Con estos resultados de PCR también se logró identificar la presencia de $\mathrm{ADN}$ de $A$. centrale en el grupo control, explicando los valores cercanos al punto de corte, considerados sospechosos en los ELISA. Asimismo, se puede inferir la transmisión mecánica por vectores, ya que las maniobras realizadas con los animales experimentales durante el presente trabajo no incluyeron posibles acciones iatrogénicas.

En los animales incluidos en la experiencia no se observaron efectos adversos a la vacuna conteniendo cepas vivas de $A$. centrale M1. La transmisión de $A$. marginale es indirecta, con excepción de la que se produce directamente de la vaca al ternero por vía transplacentaria. La transmisión indirecta se lleva a cabo por medio de artrópodos hematófagos o por instrumentos $\mathrm{u}$ objetos accionados por el hombre ${ }^{2}$.

Los transmisores de $A$. marginale en nuestro país no son conocidos con exactitud. Experimentalmente se logró la transmisión transestadial de $A$. marginale con adultos de Rhipicephalus (Boophilus) microplus (único vector que se encuentra en Argentina) y de Amblyomma neumanni (garrapata de tres huéspedes), que provenían de ninfas alimentadas sobre bovinos con infección patente ${ }^{1,4}$.

Sin embargo, un estudio realizado en dos establecimiento ubicados en la Provincia de Salta (Argentina), uno con $R$. microplus durante todo el año y el otro con presencia esporádica del mismo, mostró que las primoinfecciones con $A$. marginale eran independientes de la presencia del supuesto vector, resultando en tasas de infección del ganado similares al cabo de un año ${ }^{2}$.

Los dípteros hematófagos como Stomoxys calcitrans, ocho especies de Tabanus sp, tres especies
Tabla 1. Resultados del test ELISA a los 30 y 60 días en grupos inoculado y control.

\begin{tabular}{lccccc}
\hline grupo & $\mathrm{N}$ & \multicolumn{2}{c}{ ELISA $30 \mathrm{dpv}$} & \multicolumn{2}{c}{ ELISA $60 \mathrm{dpv}$} \\
\hline \multirow{6}{*}{ inoculados } & 151 & $2 \%$ & $\mathrm{~N}$ & $89 \%$ & $\mathrm{POS}$ \\
& 152 & $2 \%$ & $\mathrm{~N}$ & $4 \%$ & $\mathrm{~N}$ \\
& 153 & $3 \%$ & $\mathrm{~N}$ & $84 \%$ & POS \\
& 154 & $1 \%$ & $\mathrm{~N}$ & $97 \%$ & POS \\
& 155 & $79 \%$ & $\mathrm{POS}$ & $91 \%$ & POS \\
& 156 & $36 \%$ & POS & $84 \%$ & POS \\
& 157 & $12 \%$ & $\mathrm{~N}$ & $106 \%$ & POS \\
& 158 & $2 \%$ & $\mathrm{~N}$ & $2 \%$ & $\mathrm{~N}$ \\
& 159 & $13 \%$ & $\mathrm{~N}$ & $103 \%$ & $\mathrm{POS}$ \\
& 160 & $3 \%$ & $\mathrm{~N}$ & $77 \%$ & $\mathrm{POS}$ \\
\hline \multirow{6}{*}{ controles } & 171 & $6 \%$ & $\mathrm{~N}$ & $5 \%$ & $\mathrm{~N}$ \\
& 172 & $2 \%$ & $\mathrm{~N}$ & $3 \%$ & $\mathrm{~N}$ \\
& 173 & $1 \%$ & $\mathrm{~N}$ & $3 \%$ & $\mathrm{~N}$ \\
& 174 & $12 \%$ & $\mathrm{~N}$ & $4 \%$ & $\mathrm{~N}$ \\
& 175 & $4 \%$ & $\mathrm{~N}$ & $27 \%$ & $\mathrm{Sosp}$ \\
& 176 & $6 \%$ & $\mathrm{~N}$ & $28 \%$ & $\mathrm{Sosp}$ \\
& 177 & $1 \%$ & $\mathrm{~N}$ & $5 \%$ & $\mathrm{~N}$ \\
& 178 & $2 \%$ & $\mathrm{~N}$ & $2 \%$ & $\mathrm{~N}$ \\
& 179 & $10 \%$ & $\mathrm{~N}$ & $7 \%$ & $\mathrm{~N}$ \\
& 180 & $2 \%$ & $\mathrm{~N}$ & $3 \%$ & $\mathrm{~N}$ \\
\hline
\end{tabular}

$\mathrm{N}$ : número de caravana; ELISA: ensayo por inmunoabsorción ligado a enzimas; dpv: días post-vacunación; N: negativo; POS: positivo; Sosp; sospechoso.

Tabla 2. Resultados de la reacción en cadena de la polimerasa (PCR) a los 15, 30, 45 y 60 días en grupos tratado y control (dpv).

\begin{tabular}{ccccccccc}
\hline \multirow{2}{*}{ caravana } & \multicolumn{2}{l}{ PCR $15 \mathrm{dpv}$} & \multicolumn{2}{c}{ PCR $30 \mathrm{dpv}$} & \multicolumn{2}{c}{ PCR $45 \mathrm{dpv}$} & \multicolumn{2}{c}{ PCR 60 dpv } \\
\cline { 2 - 9 } & A.m. & A.c. & A.m. & A.c. & A.m. & A.c. & A.m. & A.c. \\
\hline 151 & $\mathrm{~N}$ & $\mathrm{~N}$ & $\mathrm{~N}$ & POS & N & POS & N & POS \\
155 & $\mathrm{~N}$ & POS & N & POS & N & POS & N & POS \\
157 & N & N & N & POS & N & POS & N & POS \\
171 & N & N & N & N & N & POS & N & POS \\
173 & N & N & N & N & N & POS & N & POS \\
175 & N & N & N & POS & N & POS & N & POS \\
\hline
\end{tabular}

A.m.: Anaplasma marginale. A.c.: Anaplasma centrale. N: negativo. POS: positivo.

de Culicidae ${ }^{11}$ y Haematobia irritans ${ }^{3}$ actúan como transmisores de $A$. marginale y $A$. centrale de forma mecánica. Se puede inferir la transmisión mecánica de la cepa vacunal por estos dípteros, principalmente tábanos y mosquitos.

La transmisión iatrogénica a través de agujas, descornadores, mochetas, pinzas para tatuar, bisturíes, $\mathrm{ca}$ ravaneadores y otros instrumentos, actúan como transmisores mecánicos de sangre infectada con $A$. centrale y A. marginale, constituyendo ésta una importante vía de transmisión intra-rodeo pero no entre rodeos ${ }^{6}$ . En el presente trabajo, se podría descartar esta vía de transmisión debido a los recaudos tomados durante el experimento.

Investigadores brasileños demostraron en 2013 la transmisión transplacentaria en un área de inestabili- 
dad enzoótica a partir de vacas con infección crónica (100\% seropositivas por inmunofluorescencia indirecta y $63,3 \%$ positivas a PCR) y resultando los terneros recién nacidos positivos en un $6,7 \%$ por PCR ${ }^{5}$. Si bien en este caso no se trató de un rodeo de inestabilidad enzoótica, fue necesario realizar el perfil de anticuerpos el día 0 a través de ELISA para tener la certeza de que los animales utilizados en el ensayo resultasen negativos a títulos de anticuerpos contra anaplasmosis. Asimismo, a los 15 dias post-inoculación de pudo identificar A. centrale por PCR. Cabe resaltar la utilidad de esta herramienta de diagnóstico, ya que a partir de los 15 días es posible evidenciar la presencia del agente etiológico.

En conclusión, surge que la vacuna ultracongelada de Anaplasma centrale presentó una adecuada actividad inmunogénica y no se observaron efectos adversos o reacciones post-vacunales, en la categoría de animales incluidos en el ensayo.

Esta vacuna monovalente resultaría interesante para su utilización en zonas donde la babesiosis no es endémica y redundaría en beneficios económicos para el productor, ya que resultaría menos costosa al prescindir de la tecnología que implica la producción de eritrocitos parasitados con Babesia sp, que actualmente incluye la vacuna trivalente criopreservada.

Asimismo, cabe resaltar la importancia de implementar medidas de control de los dípteros hematófagos cuando se utilizan estos métodos inmuno-profilácticos, ya que está demostrada la transmisión mecánica de la cepa vacunal.

La combinación de las técnicas de diagnóstico disponibles en nuestro país, representan una herramienta invaluable para controlar y tratar adecuadamente esta patología, que provoca grandes pérdidas en nuestros rodeos.

Agradecimientos. Al MV Sebastián Estigarribia por sus aportes en el presente trabajo. A la Secretaria de Ciencia y Técnica-UNNE y al Laboratorio Litoral Biológicos SRL por el apoyo económico.

\section{REFERENCIAS}

1. Aguirre DH et al. 1994. Transmission of Anaplasma marginale with adult Boophilus microplus ticks fed as nymphs on calves with different levels of rickettsemia. Parasite 1: 405-407.
2. Fiel C, Nari A. 2013. Enfermedades parasitarias de importancia clínica y productiva en rumiantes. Fundamentos epidemiológicos para su prevención y control, Editorial Hemisferio Sur, Montevideo (Uruguay), 752 p.

3. Foil LD, Gorham JR. 2004. Mechanical transmission of disease agents by arthropods. In: Medical Entomology (Eldridge BF \& Edman JD, edit.), Ed. Springer, New York, p. $461-514$.

4. Gaido AB. 1995. Transmission of Anaplasma marginale by the three-host tick Amblyomma neumanni under laboratory conditions. Folia Parasitol 42: 72.

5. Gonzalez HE, Cunha NA, Pappen FG, Farias NA. 2013. Transplacental transmission of Anaplasma marginale in beef cattle chronically infected in southern Brazil. Rev Bras Parasitol Vet 22: 189-193.

6. Kocan KM, Blouin EF, Barbet AF. 2000. Anaplasmosis control: past, present and future. Ann. NY Acad. Sci 916: 501-509.

7. Luciani C. 2003. Babesiosis y anaplasmosis, la "tristeza bovina”. Public. de la Estación Experimental Agropecuaria INTA, Colonia Benítez, Chaco, Argentina, p. 5-8.

8. Mangold AJ, Aguirre DH, Guglielmone AA. 1990. Postthawing viability of vaccines for Bovine babesiosis and anaplasmosis cryopreserved with glycerol. Vet Parasitol 37: 301-306.

9. Mangold, AJ. 2005. Prevención de la babesiosis y anaplasmosis. Anales de la Reunión Anual de la Asociación Argentina de Criadores de Braford (Rafaela, Santa Fe, Argentina), p. 3-4.

10. OIE-World Organisation for Animal Health. 2015. Manual terrestre de la OIE, Capítulo 2.4.1: Anaplasmosis bovina. www.oie.int/es/normas/manual-terrestre/

11. Scoles GA, Broce AB, Lysyk TJ, Palmer GH. 2005. Relative efficiency of biological transmission of Anaplasma marginale (Rickettsiales: Anaplasmataceae) by Dermacentor andersoni (Acari: Ixodidae) compared with mechanical transmission by Stomoxys calcitrans (Diptera: Muscidae). J Med Entomol 42: 668-675.

12. Torioni S et al. 1998. Detection of cattle naturally infected whit Anaplasma marginale in a region of endemicity by nested PCR and competitive enzyme linked immuno sorbent assay using recombinant major surface protein-5. $J$ Clin Microbiol 36: 777-782. 